\title{
A distance learning application based on a digital library of courseware
}

\author{
M. Marolt and M. Privošnik \\ Faculty of Computer and Information Science, \\ University of Ljubljana \\ Traška 25, 1000 Ljubljana, Slovenia \\ e-mail: \{matija.marolt,marko.privosnik\}@fri.uni-lj.si
}

\begin{abstract}
This paper presents a distance learning application currently under development at the University of Ljubljana in Slovenia. The basic idea of the application is to join learning materials on various topics and written by many teachers in a digital library of courseware. Such a digital library provides a basis for creating courses on specific topics. Our application is based on the WWW and the Java programming language and can be readily used over a high bandwidth network connection. The problem is, however, that most students usually do not have high bandwidth network connections to their homes. A possible solution to this problem arose from University of Ljubljana's co-operation in the ACTS AC-018 SMASH (Storage for Multimedia Applications Systems in the Home) project. The goal of this project is to develop a mass storage device for home usage, that can hold 13 GB (or even more) of data. It uses a linear tape drive coupled with a hard disk used for caching data from tape. If the digital library were stored on such a tape, tapes could be distributed to students, and students could use the application at their homes without the need for a network connection. We are developing an interface to the mass storage device to make this possible.
\end{abstract}

\section{Keywords}

Distance learning, WWW, Courseware, Reusability of courseware, Multimedia storage, Java 


\section{INTRODUCTION}

Recent advances in computing, especially multimedia and the Internet, offer great possibilities for educators. The World Wide Web (WWW) as a distributed hypermedia information system with capabilities that include graphics, audio and video clips, and the appearance of Java as programming language of the Internet, have given rise to a number of distance learning projects and initiatives. The educational use of computers has advanced beyond word processing and numerical calculations to include interactive tutorials with videos and learn-by-doing exercises. In fact, we could start talking about a shift from the classic lecture and textbook based teaching, which has been the way to teach for centuries, to a new level, where students are offered interactive multimedia materials with learn-bydoing examples, test questions. The teacher, of course, is still the key figure in the educational process giving lectures and guidance to students and preparing learning materials, but the way students learn can be vastly improved. Experiences show, that active "learning by doing", as opposed to "learning by seeing and hearing", can nearly double the learning effectiveness (Harger, 1996). All this shows us that these new technologies are a huge opportunity for educators.

The basic idea of distance education is "teachers are apart of learners" (Sun and Chou, 1996). In our case, distance learning is considered as a complementary process to normal learning and teaching activities, meaning that learners also have access to multimedia educational materials, when they study at home. This paper presents a distance learning application, currently under development at the University of Ljubljana in Slovenia, as an example of an educational application based on the WWW and the Java programming language. We especially address two issues we feel are very important: reusability of educational materials for different courses and dissemination of materials among students.

\section{ORGANISATION OF COURSEWARE}

Our goal is to develop a distance learning application, which would act as a framework for the development of different courses; thus it is not meant as an application for teaching a specific topic. The basis of each educational application is learning materials (courseware). This section describes the organisation of courseware within our application.

Materials are organised in two different ways (on two different levels). All the materials (on various topics, written by many teachers) are stored in a digital library of courseware. Within the digital library (lower level of organisation), these materials are organised in mind maps. Such an organisation connects different topics and subtopics in a tree-like structure (although cycles are allowed). Materials on four topics (3D computer graphics, image processing, virtual environments, and robotics) are currently being prepared at the University of 
Ljubljana and will be joined in a digital library. When developing a course on a specific topic (higher level of organisation), a teacher specifies a linear structure similar to the organisation of chapters, subchapters... in a book. Students are very familiar with such a linear structure and it encourages them to follow the course in an orderly manner, as proposed by the teacher. Linear organisation of courses is also preferred in some other distance learning environments (see Forte, 1996).

\subsection{Mind maps}

Mind mapping was developed in the late 60's by Tony Buzan (Buzan, 1974), following his research into note taking techniques. A mind map typically consists of an organic chart connecting concepts of an area of information in a hierarchical inside - out manner. Concepts are presented by words or images where the most important concepts are near the centre, and less important ones at the edges, producing a growing and organised structure composed of key concepts. Every item in a map could be the centre of another map.

The structure of mind maps is two dimensional as opposed to the one dimensional list structure of a conventional text. A mind map shows the relative importance of concepts and the way that concepts relate to each other. This helps relative significance of concepts to become evident in a more meaningful way and associations to be made easily. Mind maps help organise information into a form that is easily assimilated by the brain and easily remembered. With a nind map a bigger subject can be understood and remembered much more efficiently.

Mind maps have many advantages over ordinary linear text in being visual and easily remembered, flexible and open ended, clear in themes, structure, and relative importance, compact... (Russel, 1979).

Our application uses mind maps to structure materials in the digital library. When a teacher creates learning materials, he maps every topic to a concept in a mind map, defines its parent and child concepts (topics) and, if he wishes, defines several other attributes (such as importance, colour, picture...). These mind maps are used by the application to present the structure of each topic to students (see section 3 for more details).

\subsection{Creating courses}

To create a course on a specific topic, a teacher uses documents from the library and creates a list of references to these documents, structured as chapters, subchapters... This list defines the structure of materials in the course. The structure is linear (as in a book) and defines the path a student should follow in order to study through all of the required materials. No changing of materials in the library is necessary in order to make a particular course, a teacher simply defines the course's documents and their order.

Such an organisation tries to solve two problems. The essence of hypertext is the ability to take a particular keyword within a document and assign it a link, which points to another document carrying more information on that keyword. This is a 
very fine concept, but can introduce a lot of confusion if not used properly. Hypertext nodes may be linked together in a manner that can leave students confused as to whether or not they made through all of the material they should have read (Mengel, 1996). Such a system of links must therefore be carefully designed. Courses made with our application have a linear chapter-by-chapter organisation. A linear organisation can be easily followed by students and does not lead to confusion as can be the case in a network of hyperlinks. This does not mean, however, that documents in the library may not contain hyperlinks! These can still exist, they are just treated differently by the application (see the next section for more details).

The use of hyperlinks to bind the materials together into a course (linking various topics using hyperlinks), can lead to difficulties when a teacher wants to prepare a new course by using materials from an existing course. If nothing else, he has to correct all the links within various documents to point to new materials. In our application, the structure of materials in a course is not directly related to materials in the library (it is specified separately). Therefore, materials can be reused very easily and no correction of hyperlinks, is necessary.

\section{DISTANCE LEARNING APPLICATION}

\subsection{Creating Materials and Courses}

As mentioned in the previous section, all of the materials are stored in the digital library. The process of creating materials for the digital library and individual courses is illustrated in Figure 1.

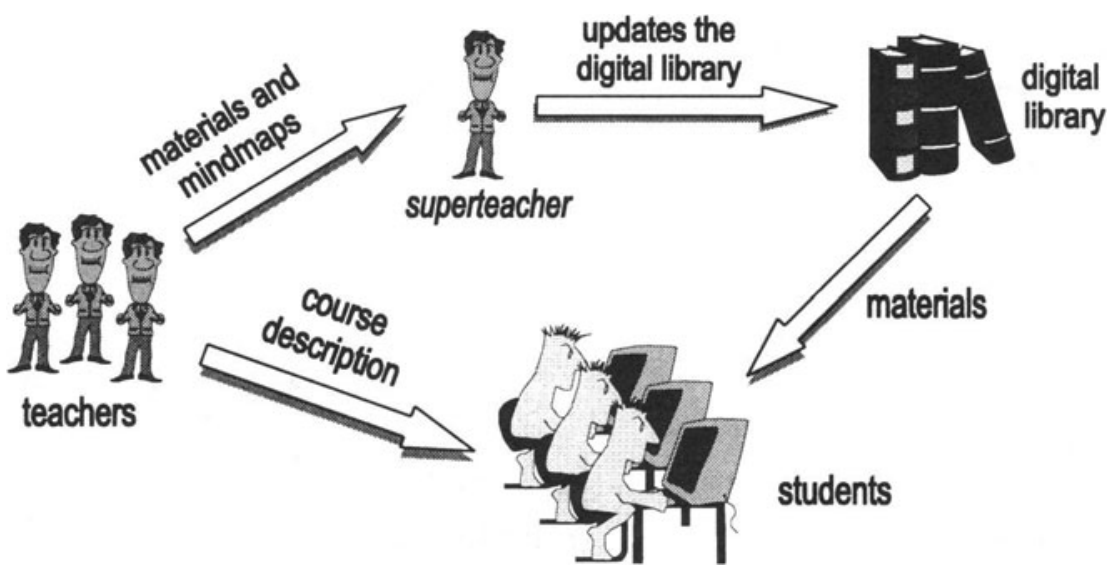

Figure 1 Creating materials and courses. 
Each teacher that wants to contribute new materials is given a set of guidelines for their preparation in order for all of the materials to have a "common look and feel". Materials are HTML documents and teachers are encouraged to use a lot of multimedia and interactive features, such as video clips, VRML files, Java applets, Tests for students, such as multiple-choice questions or learn-by-doing etc. Tests for students, such as multiple-choice questions or learn-by-doing examples should also be provided. Teachers have to organise their materials into mind maps. Each topic is represented by a concept in a mind map. Concepts are linked together and may have many additional attributes, such as importance, shape, colour, URL, position... A teacher should define the concepts and their relations in a special mind map file.

When a teacher prepares his materials and the mind map file, he sends them to a so-called "superteacher". Superteacher is a person, whose task is to organise the materials and mind map files provided by teachers and to integrate them into the digital library.

Each teacher that wishes to use the materials in the library to create a course gets a list of all the available materials and can browse the library to find the documents he wishes to include in his course. These documents can be written by the teacher himself or by another teacher. A course is then described as a list of references to documents in the digital library, organised into a sequence of chapters, subchapters, sections, subsections, etc. A teacher can also specify the level of difficulty of each topic (easy to learn, hard to lea:n,...). This sequence of references is specified in a special course file. When a teacher wants his students to study for a particular course, he only has to give them the course file and if students have access to the digital library, they can start with their studies.

\subsection{The Application}

Students can access the digital library with a WWW browser (e.g. Netscape) that supports Java. The distance learning application is written in the Java programming language and handles student's interactions with educational materials. A view of an early prototype of the application can be seen in Figure 2.

The user interface is divided into 4 sections.

On the left side, students see the chapter-based linear structure of learning materials (as provided by the teacher in the course file). This includes the title of the topic (chapter) a student is currently studying and its subtopics. Special tags will also be used to mark the level of difficulty of each topic.

The upper left part of the window contains a type of a map (only text in the current implementation) that shows how students got to the topic they are currently studying.

The toolbar includes navigation buttons for moving to the next/previous subtopic or up to the title topic in a linear manner. Other buttons will also be included, such as a "help" button, "send e-mail" button, or "start a teleconference" button (the latter if the student's computer is connected to a network providing enough bandwidth for teleconferencing). 
The main part of the application's window contains mind maps of learning materials or learning materials themselves. Mind maps are drawn according to the organisation of materials in the digital library. The title of the topic a student is currently studying is displayed as the central concept of the mind map with its related subconcepts positioned around the centre. Note that these subconcepts do not necessarily correspond exactly with the subtopics of the main topic as displayed on the left part of the screen (they are usually a superset of subtopics). The subconcepts that do correspond are marked with a special tag. When mind maps are not displayed, this window displays the actual learning materials (as can be seen in Figure 2).

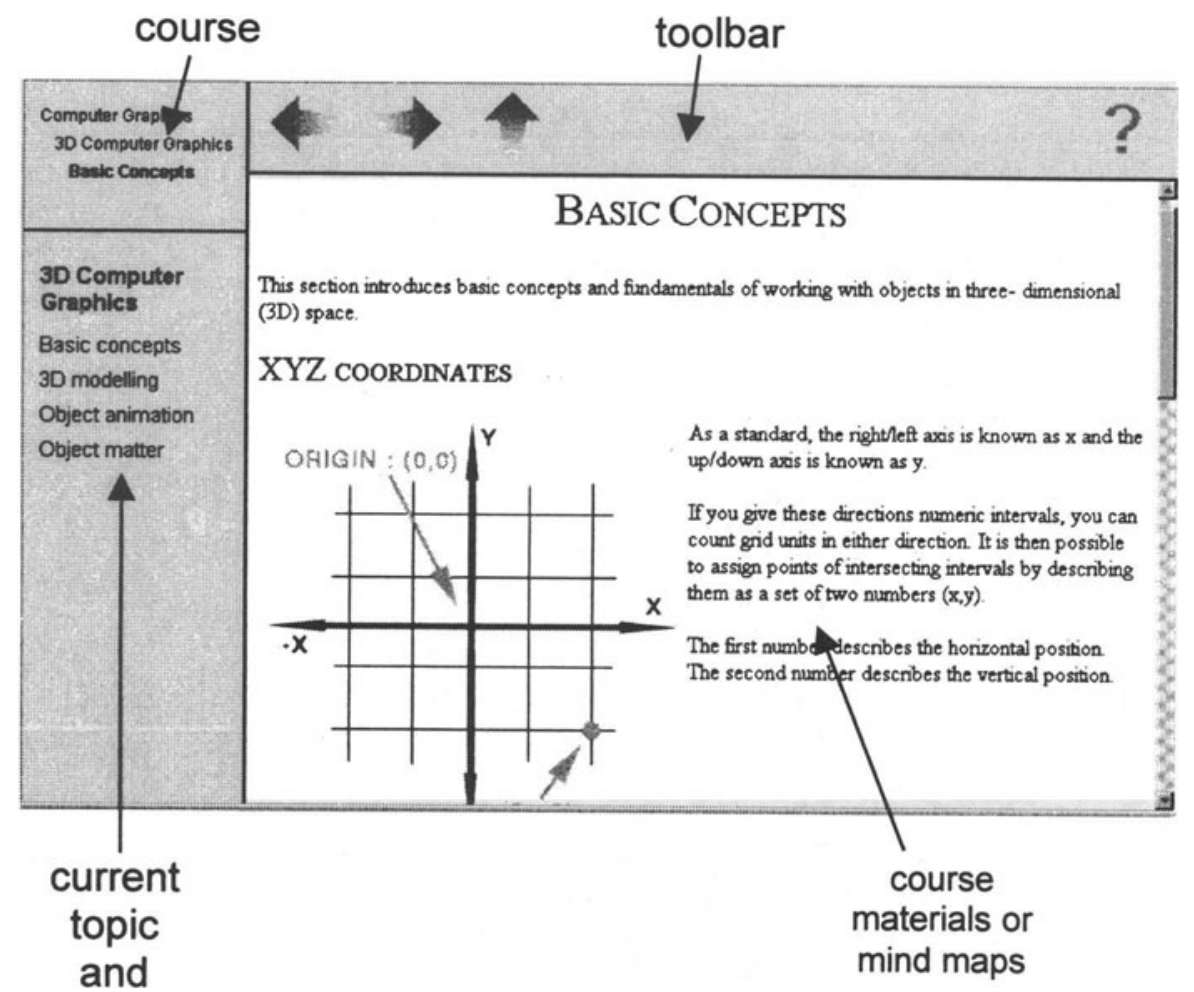

Figure 2. Application's user interface

Students can navigate through a course in various ways:

- by clicking on the next/previous buttons, students can browse the materials in a linear manner, as recommended by the teacher. When navigating in this way, students can be sure that they have studied all of the required materials. 
- when mind maps are displayed, students can browse the materials by clicking on concepts within mind maps. As noted before, it is not necessary for a topic and its subtopics, defined by a teacher as required materials a student should study (and displayed on the left side of the window) to directly correspond to the mind map of that particular topic. The mind map usually includes more items for a particular topic than students are required to learn for a course. Such organisation of materials encourages students to explore new topics, which are related to a particular topic, but are not considered as required knowledge. When students choose a topic that is not part of a designed course, the topic opens up in a new window (containing only the hypertext and mind maps; without the toolbar and the list of chapters). Students are then free to explore that topic. When they finish, they simply close the window and continue where they left off (somewhere in the middle of materials they are required to study). This ensures that when students wander away, exploring new materials and following hyperlinks, they always come back to the topic in the required part of materials, they last studied.

- when materials are displayed, students can navigate by clicking on hypertext links within the materials. As when exploring non-required topics through mind maps, a new window opens up with the contents of the hyperlink. When students finish with browsing, they close the window and return to the topir, they last studied.

In addition to all the features described, we plan to add the possibility of displaying lists of particular types of materials to students. For example: students might need a list of all the test questions in the course (multiple-choice questions or learn-bydoing examples), a list of all the movies or animations or a list of topics of a particular difficulty level. Such a list would then be displayed and students could quickly browse its content.

\section{MAKING THE APPLICATION AVAILABLE TO STUDENTS}

If we want students to be able to use our distance learning application at home, we have to provide them with access to the digital library. The application itself is based on the WWW and Java, which are two Internet concepts and is therefore suited for use over the Internet. The idea of a large digital library, which would reside on a server somewhere on the network, further emphasises such a concept. If a good network infrastructure is available, the application can be readily used over the network.

The only problem is, that most students do not have high bandwidth network connections to their homes or at the campus. What they usually have is a modem connection or perhaps a basic-rate ISDN connection, but since learning takes time, these are far too expensive, and also don't have enough bandwidth for transfer of good quality video materials, which are an essential part of courses. Making CDROMs and distributing them among students might seem like a good solution, but 
CD-ROMs could be only be used for distribution of a single course or just a part of a course to students. The concept of a digital library containing not only the materials a student has to learn, but also other useful materials could not be supported using CD-ROMs, since they do not contain enough storage space.

A possible solution to this problem arose from University of Ljubljana's cooperation in the ACTS AC-018 SMASH (Storage for Multimedia Applications Systems in the Home) project. The goal of this project is to develop a mass storage device for home usage, that can store $13 \mathrm{~GB}$ (or even more) of data. The device consists of a linear tape drive, coupled with a hard disk used for caching data from tape (this gives it near-random access to data). The storage device's main purpose is to record cable-TV MPEG-2 digital video streams, but it can also be connected to a computer and used as a mass storage device.

This means that the whole digital library could be stored on a single tape. Each student would then obtain a copy of such a tape and (provided he has the mass storage device at home) could run our application at home without the need for a constant high bandwidth network connection. We are developing an interface towards the mass storage device to make this possible.

\section{CONCLUSION}

The motivation behind the development of our distance learning application is to increase the interest of teachers in the development of interactive multimedia materials and also to encourage co-operation among teachers when developing such materials and courses. We feel that our idea of a digital library of courseware provides a good basis for such co-operation. It allows materials in the digital library to be used and reused very easily and also encourages students to explore new topics as they study through the required path of a course.

On the other hand, we are trying hard to make this application accessible to students everywhere, not just at the university, where a good network infrastructure is present, but also at home. We hope, that our involvement in the ACTS project will make this possible.

Currently, our application is still in the implementation phase. We have an early application prototype, which already works as described in the paper, but the user on interface and display of mind maps still need to be improved. We are also working on the interface towards the SMASH storage device, which should be completed soon, and are also preparing courseware on four different topics (computer graphics, computer vision, digital signal processing and robotics). The courseware will be integrated in the digital library and will be used for undergraduate studies of computer science and electrical engineering at the University of Ljubljana. 


\section{ACKNOWLEDGEMENTS}

The authors thank all the members of University of Ljubljana SMASH group, especially prof. Saša Divjak, prof. Jure Tasi, dr. Aleš Leonardis, dr. Jasna Maver, dr. Marjan Leban, Urban Burnik and Andrej Košir.

\section{REFERENCES}

ACTS AC-018 SMASH project Deliverable \#5, a0018/tud/it/ds/p/ 005/b1, 1996. Buzan, T. (1974) Use your Head. BBC Publications, London.

Harger, R.O. (1996) Teaching in a Computer Classroom with a Hyperlinked Interactive Book. IEEE Transanctions on Education., 39-1, 327-335.

Mengel, S.A. (1996) The Need for a Hypertext Instructional Design Methodology. IEEE Transactions on Education, 39-1, 375-380.

Russel, P. (1979) The Brain Book. RKP, London.

Sun, C.T. and Chou, C. (1996) Experiencing CORAL: Design and Implementation of Distant Cooperative Learning. IEEE Transactions on Education, 39-1, 357366.

Wentland Forte, M., McMurray E. and Simillon, F. (1996) Teaching Informatics with ARIANE: An Experimental Internet-Based Pedagogical Environment. Proceedings of Computer Aided Learning and Instruction in Science and Engineering, CALISCE'96, San Sebastian, Spain.

\section{BIOGRAPHIES}

Matija Marolt is a young researcher at the Faculty of Computer and Information Science, University of Ljubljana, Slovenia. His research interests include computer music, virtual reality and hypermedia. He received his diploma in computer science from University of Ljubljana in 1995. He is currently a PhD student at the Faculty of Computer and Information Science, University of Ljubljana.

Marko Privošnik is a teaching assistant at the Faculty of Computer and Information Science, University of Ljubljana, Slovenia. His research interests include cognitive science, human-computer interaction, intelligent user interfaces and hypermedia. He received his diploma and MS degree in computer science from University of Ljubljana in 1992 and 1997, respectively. He is currently a PhD student at the Faculty of Computer and Information Science, University of Ljubljana. 